\title{
SYNTHESIS AND CHARACTERIZATIONS OF METALLIC NANOPARTICLES IN CHITOSAN BY CHEMICAL REDUCTION
}

\author{
YASNA LEÓN ${ }^{1 *}$, GALO CÁRDENAS $S^{2}$ MAURICIO ARIAS ${ }^{l}$ \\ ${ }^{1}$ Departamento de Ciencias Básicas, Universidad Santo Tomás, Iquique \#3991, Antofagasta, Chile. \\ ${ }^{2}$ Centro de Biomateriales y Nanotecnología, Av. Collao \# 1202, Universidad del Bío Bío, Concepción, Chile
}

\section{SUMMARY}

One of the applications of chitosan is based on its ability to stabilized metallic nanoparticles with minimum chitosan metal molar ratio.

This work describes the synthesis and characterization of $\mathrm{Ag}, \mathrm{Au}, \mathrm{Pt}$, and $\mathrm{Cu}$ nanoparticles stabilized by chitosan through chemical reduction of metallic salts by sodium borohydride $\left(\mathrm{NaBH}_{4}\right)$.

The properties of bionanocomposites were studied in terms of their surface plasmon resonance, crystalline structure, average diameter size, particle distributions and functional groups. The samples were characterized by TEM, electron diffraction, UV-Visible and FTIR. The stability of the colloids at room temperature were also measured. A high stability for the colloidal dispersion with chitosan can be observed ( $>$ three months). We found that TEM studies show a size distribution between 6 and $10 \mathrm{~nm}$, depending on metals and chitosan metal relation. Electron diffraction analysis for the metallic nanoparticles shows the presence of Ag, Au, $\mathrm{Pt}$ and $\mathrm{Cu}$. The FT-IR exhibit the presence of the chitosan in the stabilisation of metallic nanoparticles.

Keywords: Nanoparticles, Chitosan, TEM.

\section{INTRODUCTION}

The noble metals group including silver, gold and platinum in nanometer scale size, which are responsible for different properties, concerning the bulk material, renders them suitable for applications in catalysis, electronic, nonlinear optics and biomaterial applications ${ }^{1-4}$.

Concerning the synthesis of metal nanoparticles many methods have been mentioned in literature ${ }^{5-9}$. The most significant problem in nanoparticles synthesis is stabilization, where the particles tend to agglomerate, increase in size with subsequent flocculation, this agglomeration issue can be avoided by the use of a good support. The use of polymers for the synthesis of metallic particles, has proven to be an alternate stabilizing agent since they allow better particle size control. Polymers such as polyvinylpyrrolidone (PVP), polyvinyl alcohol and others have been reported to be metal nanoparticles stabilizers ${ }^{10-13}$ Polysaccharides have been used in the synthesis of nanoparticles ${ }^{14-16}$ and biopolymers such as chitosan and its derivatives, cellulose, alginate and pectin, are compelling stabilizing agents, due to their excellent synergy and bifunctional expected effects ${ }^{17-18}$.

Chitin ( $\beta-1,4-2$ acetamide-2-deoxy-D-glucopyranose), is the most important natural polysaccharide after cellulose and it is found in the structure of a wide number of invertebrates, the material source for chitosan ( $\beta-1,4-2$ amine-2-deoxy-D-glucopyranose) is obtained by total or partial $\mathrm{N}$-deacetylation of chitin; chitosan is also soluble in acidic media and used in the synthesis of nanoparticles. The presence of largely free amino and hydroxyl groups in the polymer chain of chitosan makes it one of the most versatile materials to be studied, because of the possibility of performing a wide variety of modifications, such as anchoring enzyme reactions, grafting reactions and obtaining crossed films. Due to its biological properties its has a variety of applications in biomedicine, food processing and metal chelating agents for the removal of metallic impurities ${ }^{19-20}$. In the preparation of silver, gold, platinum and palladium metallic nanoparticles with chitosan it been reported as a stabilizer, producing particles with relatively large average diameters ${ }^{21-22}$.

The reported methods for the preparation of chitosan-stabilized metallic nanoparticles include: in-situ precipitation, radiation methods, sonochemical reduction, electrochemical reduction, and other techniques that use physical and chemical vapour deposition as well as and reduction by reducing agents $\mathrm{s}^{23-26}$.

One of the methods used for the preparation of $\mathrm{Ag}$ and $\mathrm{Au}$ nanoparticles, is the metallic salts solution chemical reduction, in water or organic solvent, using citrate ascorbic acid, hydrazine or $\mathrm{NaBH}_{4}$, as reducing agents ${ }^{27}$.

This work reports the synthesis and characterization of of $\mathrm{Ag}, \mathrm{Au}, \mathrm{Pt}$ and $\mathrm{Cu}$ nanoparticles via chemical reduction method, using chitosan suspension to prevent aggregation of metallic nanoparticles and $\mathrm{NaBH}_{4}$ as reduction agent.

\section{EXPERIMENTS}

Chitosan was supplied by Quitoquimica (Chile), with $92 \%$ of desacetylation and molecular weight of $178000 \mathrm{~g} / \mathrm{mol}$.

\section{Preparation of the chitosan- metallic nanoparticles}

An aliquot of $2 \mathrm{ml}$ of an aqueous solution of metallic salts $0.01 \mathrm{M}$ was transferred to an Erlenmeyer flask. The solution was vigorously stirred; $50 \mathrm{~mL}$ of a $0.2 \% \mathrm{v} / \mathrm{v}$ acid acetic solution of chitosan were added. Stir at least 20 minutes. $5 \mathrm{~mL}$ of aqueous solution $\mathrm{NaBH}_{4} 0.2 \mathrm{M}$ were added. The mixture was stirred for approximately 2 hours to complete reaction. The appearance of a brown colour in about $1 \mathrm{~min}$, indicated the formation of chitosan-metal nanoparticles.

\section{Transmission electron microscopy (TEM)}

Transmission electron micrographs were obtained with a JEOL JEM 1200 EXII with $4 \AA$ resolution using copper or nickel grids coated with carbon foil. A drop of the colloid was placed on a 150-mesh copper or nickel grid and allowed to dry. The particle size was determined by optical measurements, the diameters of a specific particle population were measured randomly. The data set was represented in frequency histograms, to which distributions of the Gaussians and normal type were adjusted to obtain the respective measurements.

\section{Electron Diffraction}

Electron Micrographs were obtained on a JEOL JEM 1200 EXII, the micrographs were obtained using $120 \mathrm{kV}, 60 \mathrm{~cm}, \mathrm{~K}: 4.209 \AA$. The calibration was carried out with Au film (Aldrich Chemical 99.99\%) evaporated over a copper grid. The deposition was carried out using an Edwards 5.150 Evaporator.

FT-IR studies

Infrared spectra were measured by using a FT-IR Nicolet Change 330 spectrophotometer coupled to a PC with Omnis software analysis. Spectra were recorded at a resolution $4 \mathrm{~cm}^{-1}$ and 128 scans were accumulated between 350 and $4000 \mathrm{~cm}^{-1}$.

UV-Vis absorption

The absorption spectra of the nanocomposite were measured at $25^{\circ} \mathrm{C}$ in a Spectronic Genesis 2 Spectrophotometer, using quartz cells. The spectra of the composite in $0.1 \% \mathrm{v} / \mathrm{v}$ acetic acid were obtained. The background was set up with the proper solution and then each sample was examined.

\section{RESULTS AND DISCUSSION}

The $\mathrm{Au}, \mathrm{Ag}, \mathrm{Pt}$ and $\mathrm{Cu}$ nanoparticles synthesis were carried out by the known method of chemical reduction using $\mathrm{NaBH}_{4}$ as reducing agent and chitosan as a stabilizer, since there are amino and hydroxyl groups in its structure.

Theoretical and experimental information indicate demonstrates that chitosan and metals ions form coordination bonds. The metal ion is bonded to an amino group of chitosan and metal ions are coordinated into several amino groups in the same polymer or different polymers of chitosan. Most recent studies of metal complexes of $\mathrm{Cu}$ and $\mathrm{Fe}$ show that these ions bind to both groups - $\mathrm{NH}_{2}$ and - $\mathrm{OH}$ where chitosan and other polymers can bind chain to form a complex ${ }^{28}$. 
The formation of colloidal nanoparticles is accompanied by colour changes in time, from colourless to pale yellow and finally to red or dark brown depending of the metal. The change of color of the precursor solutions is a characteristic in the formation of metal nanoparticles with some stabilizing agent ${ }^{7}$.

The stability of the nanoparticles was measured until particle precipitation at room temperature. Clear dependence of the stability regarding nanoparticles size and chitosan/metals ratio was not found. Table I summarizes the stability with chitosan and average particle size obtained by TEM.

Table I. Stability and particle size of $\mathrm{Ag}, \mathrm{Au}, \mathrm{Pt}$ and $\mathrm{Cu}$ with chitosan.

\begin{tabular}{|c|c|c|c|c|}
\hline \multirow{2}{*}{ Metals } & \multirow{2}{*}{ Ratio } & \multirow{2}{*}{$\begin{array}{c}\text { Stability } \\
\text { (days) }\end{array}$} & $\begin{array}{c}|c| \\
\text { Particle size } \\
(\mathrm{nm})\end{array}$ & $\mathrm{SD}(\mathrm{nm})$ \\
\cline { 4 - 5 } & & & 5.9 & 1.4 \\
\hline $\mathrm{Ag}$ & $2: 1$ & $<30$ & 6.4 & 1.9 \\
\hline $\mathrm{Cu}$ & $4: 1$ & $<30$ & 6.0 & 1.7 \\
\hline & $2: 1$ & $<30$ & 6.3 & 2.1 \\
\hline $\mathrm{Pt}$ & $4: 1$ & $<30$ & 8.0 & 1.3 \\
\hline & $2: 1$ & $<30$ & 8.5 & 2.7 \\
\hline $\mathrm{Au}$ & $2: 1$ & $<30$ & 8.1 & 2.3 \\
\hline & $4: 1$ & $<30$ & 9.5 & 2.8 \\
\hline
\end{tabular}
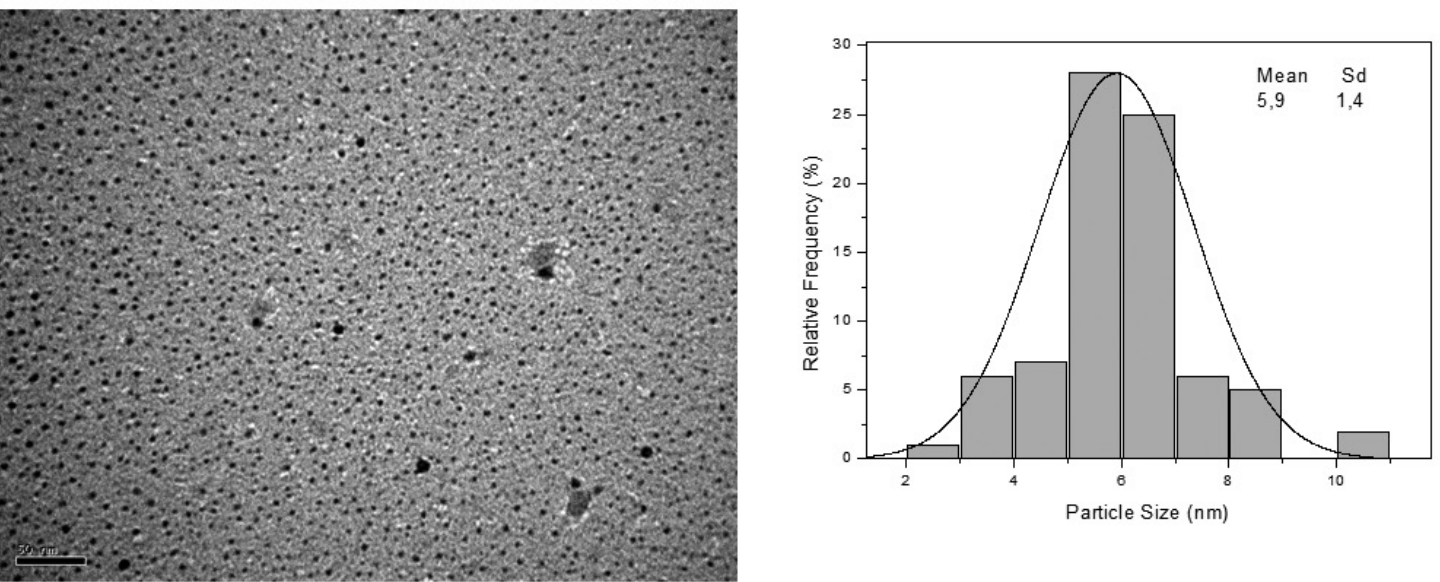

Fig. 1 Electron Micrograph (100 K) in bright field and histogram of Ag-Chitosan (2:1).
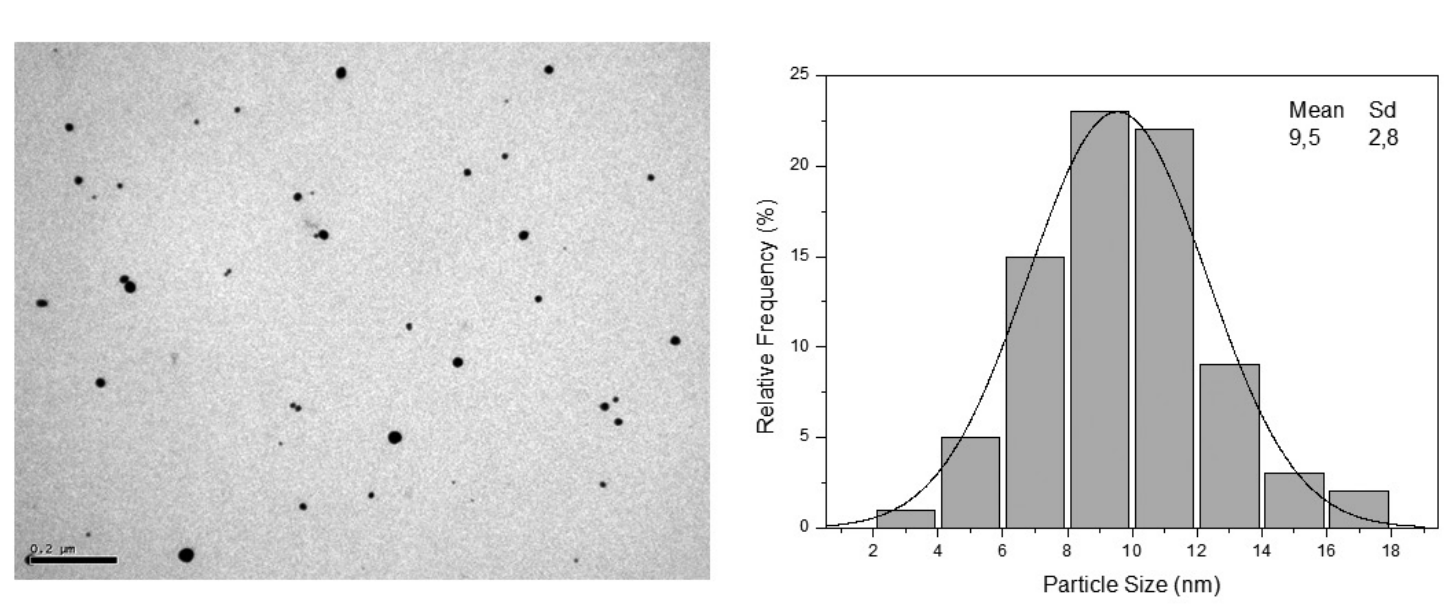

Fig. 2 Electron Micrograph (100 K) in bright field and histogram of Au-Chitosan (4:1)
The morphology of the monodispersed metallic nanoparticles was observed. The TEM studies of the metallic nanoparticle were obtained against bright and dark fields. The micrographs show particles of an apparently spherical and uniformly dispersed in the polymeric matrix. The size of the particles is represented in a histogram, to calculate the size distribution and normal deviation (Fig. 1, 2 and 3). The micrographs can be compared with previous reports of $\mathrm{Ag}$ and $\mathrm{Cu}$ nanoparticles stabilized with chitosan prepared by other synthesis methods ${ }^{21,23}$.

We observed that the particle size fluctuated between 5.9 and $9.5 \mathrm{~nm}$ for the all series, this is summarized in table 1 . The molar ratio metals/ chitosan was increased, the particle size increased independently from the metals used. The results are similar to those reported for polymeric matrices stabilized metal nanoparticles, which have a particle size between 5 and $10 \mathrm{~nm}^{28-29}$ and smaller for nanoparticles supported on modified chitosan which show particle ze close to $20 \mathrm{~nm}^{21}$. This is due to a greater dispersion of metal ions in the polymer matrix thus forming metal atoms that have smaller particle size avoiding agglomeration.

The results demonstrate that the used chemical reduction method, allowed to obtained uniformly distributed monodispersed particles.

The electron diffraction pattern collected during TEM images of the selected area, exhibits rather sharp spots with diffuse rings, confirmed the presence of amorphous particles formed by very small crystallites (see Fig. 4, 5). It is clear from the images, that the metallic nanoparticles are uniformly distributed over a polymer matrix with out any phase separation, no evidence of metal oxides in the matrix, it is reported that chitosan acts as a controller nucleation and minimizing oxidation reactions on the surface of the particles ${ }^{30-31}$ (see table II). 

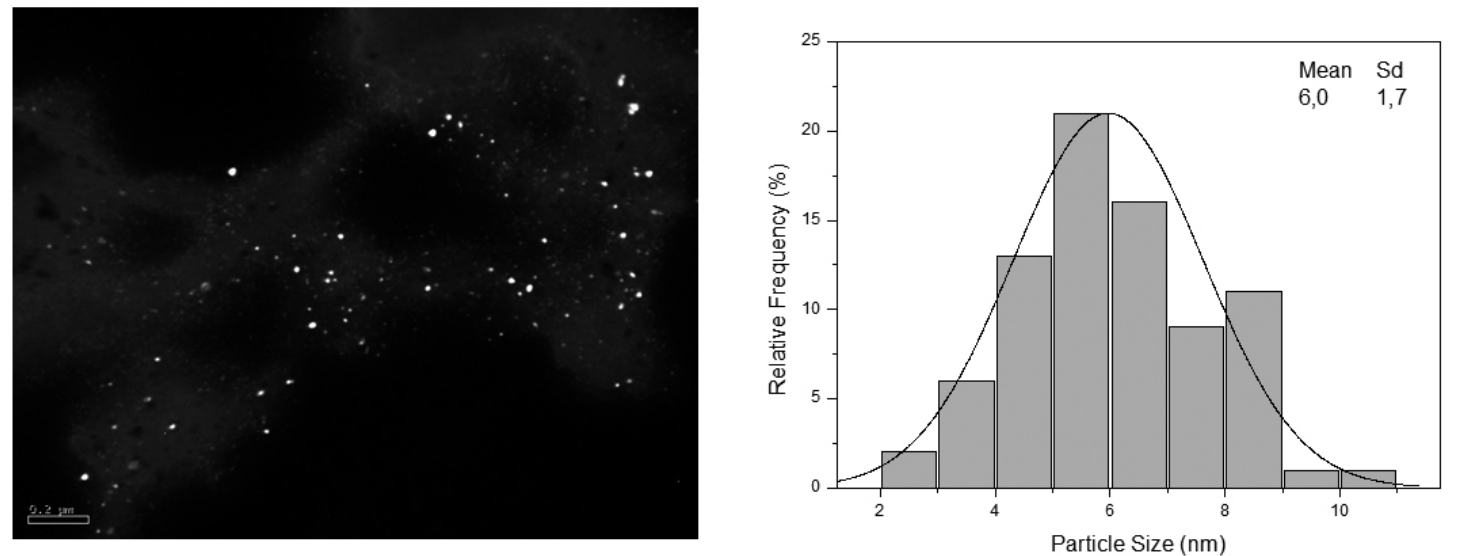

Fig. 3 Electron Micrograph (100 K) in dark field and histogram of Cu-Chitosan (2:1)

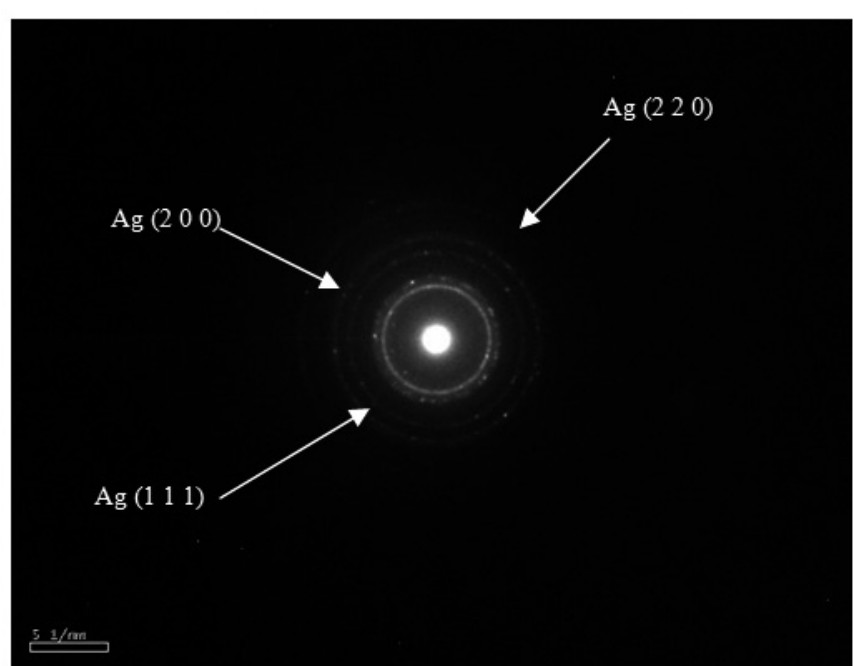

Fig. 4 Electron diffraction of Ag particle.

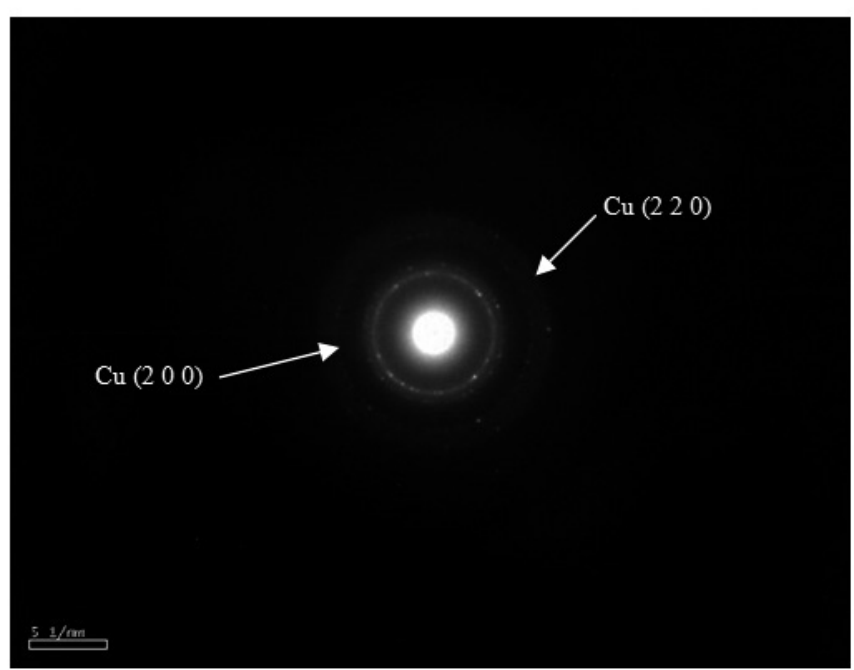

Fig. 5 Electron diffraction of $\mathrm{Cu}$ particle.
Table II. Electron diffraction pattern of $\mathrm{Ag}$ and $\mathrm{Cu}$-chitosan.

\begin{tabular}{|c|c|c|c|}
\hline Metal & $\begin{array}{c}\text { Diameter } \\
(\boldsymbol{c m})\end{array}$ & $\boldsymbol{D}_{\text {hkl }}(\boldsymbol{A})$ & Phase \\
\hline \multirow{3}{*}{$\mathrm{Ag}$} & 1.791 & 2.350 & $(2.359)^{\mathrm{a}}(111)$ \\
& 2.056 & 2.047 & $(2.044)^{\mathrm{a}}(200)$ \\
& 2.910 & 1.446 & $(1.445)^{\mathrm{a}}(220)$ \\
\hline \multirow{2}{*}{$\mathrm{Cu}$} & 2.332 & 1.805 & $(1.810)^{\mathrm{a}}(200)$ \\
& 3.289 & 1.279 & $(1.280)^{\mathrm{a}}(220)$ \\
\hline
\end{tabular}

${ }^{a}$ Data obtained from literature ${ }^{32}$

The formation of metallic nanoparticles and chitosan was confirmed by Fourier Transform infrared (FTIR) measurements. Fig 6 shows FT-IR chitosan, Ag-chitosan, Au-chitosan, Cu-chitosan an Pt- chitosan composites.The characteristic band for chitosan was observed in the infrared spectrum around $3425 \mathrm{~cm}^{-1}$ and $2926 \mathrm{~cm}^{-1}$ attributed to $\mathrm{N}-\mathrm{H}, \mathrm{O}-\mathrm{H}$ and C-H stretching band. The peaks at $1627 \mathrm{~cm}^{-1}$ and $1555 \mathrm{~cm}^{-1}$ were assigned as amide band of chitosan Bands at $1085 \mathrm{~cm}^{-1}$ were assigned to the skeletal vibration of C-O stretching ${ }^{33}$.

Bands attributed to $\mathrm{OH}$ and $\mathrm{NH}_{2}$ have low frequency and a slight displacement with respect to pure chitosan. The attachment of metallic nanoparticles to nitrogen atoms in the chitosan reduced the vibration intensity of the $\mathrm{N}-\mathrm{H}$ bond $^{34}$. Table 3 summarizes more relevant bands of the $\mathrm{Ag}, \mathrm{Au}, \mathrm{Pt}$ and $\mathrm{Cu}$ stabilized by chitosan.

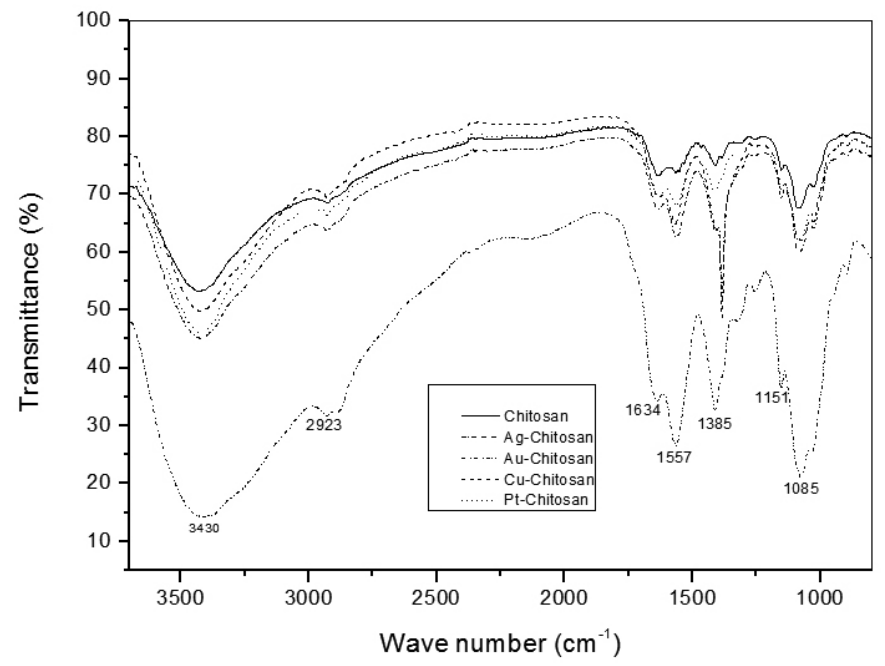

Fig 6. FTIR spectrum of chitosan, Ag-chitosan, Au-chitosan, Cu-chitosan an Pt- chitosan composites. 
Table III. FTIR bands of the metallic nanocomposite.

\begin{tabular}{|c|c|c|c|c|c|c|}
\hline \multirow{2}{*}{$\begin{array}{c}\text { Nanocomposite } \\
\text { Chitosan }\end{array}$} & \multicolumn{6}{|c|}{ IR bands } \\
\hline & $\begin{array}{l}3425 \\
v \mathrm{~N}-\mathrm{H} \\
v \mathrm{O}-\mathrm{H}\end{array}$ & $\begin{array}{l}2926 \\
v \mathrm{C}-\mathrm{H}\end{array}$ & $\begin{array}{c}1627 \\
v \mathrm{C}=\mathrm{O} \\
\text { Amide }\end{array}$ & $\begin{array}{c}1555 \\
\delta \mathrm{N}-\mathrm{H}\end{array}$ & $\begin{array}{c}1403 \\
\delta \mathrm{N}-\mathrm{H}\end{array}$ & $\begin{array}{l}1076 \\
\text { vC-O }\end{array}$ \\
\hline $\mathrm{Au} /$ Chitosan & $\begin{array}{l}3430 \\
v \mathrm{~N}-\mathrm{H} \\
v \mathrm{O}-\mathrm{H}\end{array}$ & $\begin{array}{l}2923 \\
v \mathrm{C}-\mathrm{H}\end{array}$ & $\begin{array}{c}1634 \\
v \mathrm{C}=\mathrm{O} \\
\text { Amide }\end{array}$ & $\begin{array}{c}1557 \\
\delta \mathrm{N}-\mathrm{H}\end{array}$ & $\begin{array}{c}1385 \\
\delta \mathrm{N}-\mathrm{H}\end{array}$ & $\begin{array}{l}1085 \\
v \mathrm{C}-\mathrm{O}\end{array}$ \\
\hline $\mathrm{Ag} /$ chitosan & $\begin{array}{l}3412 \\
v \mathrm{~N}-\mathrm{H} \\
v \mathrm{O}-\mathrm{H}\end{array}$ & $\begin{array}{l}2919 \\
v \mathrm{C}-\mathrm{H}\end{array}$ & $\begin{array}{c}1632 \\
v \mathrm{C}=\mathrm{O} \\
\text { Amide }\end{array}$ & $\begin{array}{c}1555 \\
\delta \mathrm{N}-\mathrm{H}\end{array}$ & $\begin{array}{c}1407 \\
\delta \mathrm{N}-\mathrm{H}\end{array}$ & $\begin{array}{r}1062 \\
v \mathrm{C}-\mathrm{O}\end{array}$ \\
\hline $\mathrm{Pt} /$ chitosan & $\begin{array}{l}3430 \\
v \mathrm{~N}-\mathrm{H} \\
v \mathrm{O}-\mathrm{H}\end{array}$ & $\begin{array}{l}2923 \\
v \mathrm{C}-\mathrm{H}\end{array}$ & $\begin{array}{c}1634 \\
v \mathrm{C}=\mathrm{O} \\
\text { Amide }\end{array}$ & $\begin{array}{c}1557 \\
\delta \mathrm{N}-\mathrm{H}\end{array}$ & $\begin{array}{c}1411 \\
\delta \mathrm{N}-\mathrm{H}\end{array}$ & $\begin{array}{l}1075 \\
v \mathrm{C}-\mathrm{O}\end{array}$ \\
\hline $\mathrm{Cu} /$ chitosan & $\begin{array}{l}3421 \\
v \mathrm{~N}-\mathrm{H} \\
v \mathrm{O}-\mathrm{H}\end{array}$ & $\begin{array}{l}2932 \\
v \mathrm{C}-\mathrm{H}\end{array}$ & $\begin{array}{c}1625 \\
v \mathrm{C}=\mathrm{O} \\
\text { Amide }\end{array}$ & $\begin{array}{c}1557 \\
\delta \mathrm{N}-\mathrm{H}\end{array}$ & $\begin{array}{c}1385 \\
\delta \mathrm{N}-\mathrm{H}\end{array}$ & $\begin{array}{l}1067 \\
v \mathrm{C}-\mathrm{O}\end{array}$ \\
\hline
\end{tabular}

The UV-visible absorption spectrum of the metallic nanocomposites $(200-700 \mathrm{~nm})$ was carried out in acetic acid solution. UV-visible absorption spectrum of Ag-chitosan and Pt- chitosan is shown in Fig.7. The Pt and Ag chitosan shows absorbance at around $200-300 \mathrm{~nm}$, this is associated with interband transitions, being this a characteristic property of the metallic nanoparticles consistent with the reports by Creighton and Eadon ${ }^{35}$ and for nanoparticles of $10 \mathrm{~nm}$. The Ag nanoparticles exhibing optical absorbance of at $405 \mathrm{~nm}$ ( $\mathrm{Au}$ and $\mathrm{Cu}$ present band $510 \mathrm{~nm}$ ), attribuited to the excitation surface plasmon vibrations of metallic atoms, the color change in the nanometer range is the evidence for this optical phenomenon ${ }^{36}$.

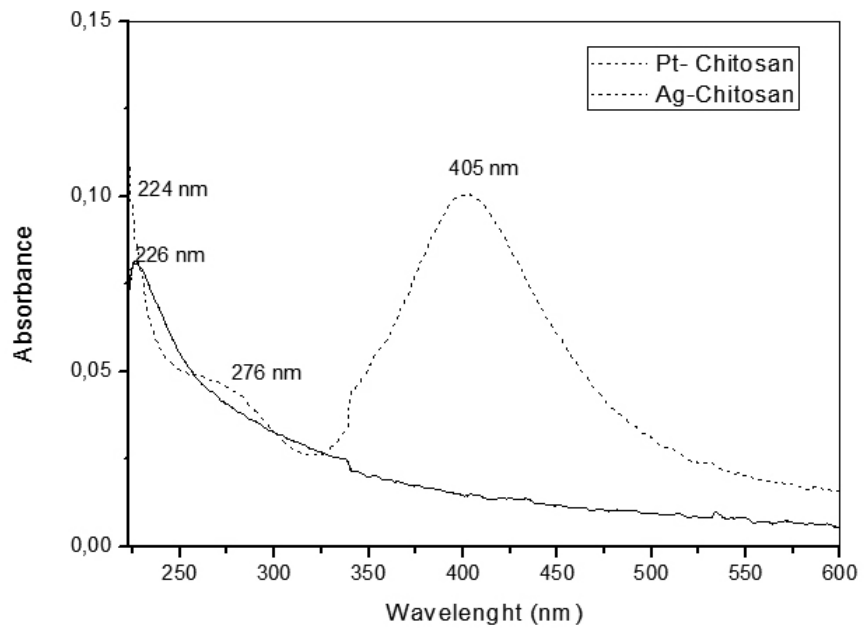

Fig. 7.- UV-Vis absorption spectrum of Ag-chitosan and Pt-chitosan.

\section{CONCLUSIONS}

The metallic nanoparticles were obtained by their reduction and nucleation in the chitosan polymers. The nanoparticles were produced in chitosan aqueous solutions by chemical reduction at room temperature, the metals nanoparticles become attached to the polymer, thus providing in a single step synthesis and stabilization, by this method small and spherical particles are produced with size distribution average diameter 6 and $10 \mathrm{~nm}$, it is suggested (here) that three parameters are the cause for the morphology, stability and particle size distribuition, these are: concentration of metals, polymer concentration and amount of reducing agents. The affinity of chitosan with transition metals is due to the presence of amino group.

\section{ACKNOWLEDGEMENTS}

The author would like to thank the financial support of Grant N000012866 Universidad Santo Tomás.

\section{REFERENCES}

1. K. Sannegowda, A. Shambhulinga, N. Manjunatha, M. Imadadulla, M. Hojamberdiev, Dyes and Pigments, 120, 155, (2015)

2. X. Liu, H. Cheng, P. Cui, Applied Surface Science. 292, 695, (2014)

3. N. Misra, M. Rapolu, S. Rao, L. Varshney, V. Kumar, Optics \& Laser Technology. 79, 24, (2016)

4. A. Akbari-Sharbaf, S. Ezugwu, M. Shafiq, M. Cottam, G. Fanchini, Carbon. 95, 199 (2015)

5. G. Cárdenas, Y. León, Y. Moreno, O. Peña, Colloid. Polim. Sci. 284, 644, (2006)

6. C. Chin Yu, Y. Chuan Liu, K. Hsuan Yang, C. Ching Li, C. CaiWang, Materials Chemistry and Physics. 125, 109, (2011)

7. S. Boufi, M. Rei Vilar, A. Ferraria, A. Botelho do Rego, Colloids and Surface A: physicochem. Eng. Aspects. 439, 151, (2013)

8. Y.León, I. Brito, G. Cárdenas, O. Godoy, J. Chil. Chem. Soc. 54, 1, 51, (2009)

9. T.C. Rocha, H. Winnischofer, E. Westphal, D. Zanchet, J. Phys. Chem. C. 111, 3901, (2007)

10. D. Özhava, N.Z. Kılıçaslan, S. Özkar, Applied Catalysis B: Environmental, 162, 573, (2015)

11. L. Hu, A. Pfirman, G. Chumanov, Applied Surface Science, 357, 1587, (2015)

12. X. Yan, H. Liu, K. Liew, J. Mater Chem. 11, 3387, (2001)

13. T. Teranishi, M. Miyake, Chem. Mater. 10, 594, (1998)

14. P. Geetha, M.S. Latha, S. Pillai, B. Deepa, K. S. Kumar, M. Koshy, J. Molecular Structure, 1105, 54, (2016)

15. H. Huang, X.Yang, Colloid Surf. A: Physicochemistry Engineering Aspects. 226, 77, (2003)

16. D. Wei, W. Qian, Colloid Surf. B: Biointerfaces. 62, 136, (2008)

17. P. Kumar, J. Dutta, V. Tripathi, J. Scientific and Industrial Research. 63, 20, (2004)

18. H. Yi, L. Wu, W. Bentley, R. Ghodssi, G. Rubloff, J. Cunver, G. Payne, Biomacromolecules. 6, 288, (2005)

19. G. Cárdenas, E. Taboada, G. Cabrera, J. Chil. Chem. Soc. 48, 1, 7, (2003)

20. G. Cárdenas, J. Díaz, M. Meléndrez, C. Cruzat, A. García, Polym. Bull. 62, 511, (2009)

21. A. Tiwari, A. Mishra, A. Kuvarega, B. Mamba. Carbohydrate Polymers. 92, 1402, (2013)

22. L. Wu, S. Shafii, M. Nordin, K. Liew, J. Li. Materials Chemistry and Physics. 137, 493, (2012)

23. G. Cárdenas, J. Díaz, M. Meléndrez, C. Cruzat, O. Peña, Colloid Polym Sci. 289, 21, (2011) 
24. A. Stevenson, D. Blanco, S. Civit, S. Antoranz, A. iglesias, S. Trigueros, Nanoscale research Letters, 7, 151, (2012)

25. J. An, Q. Luo, X. Yuan, D. Wang, X. Li, J. Appl. Polym. Sci.120, 3180, (2011)

26. D. Wei, Y. Ye, X. Jia, C. Yuan, W. Qian, Carbohydrate Research. 345, 74, (2010)

27. N. Zain, A. Stapley, G. Shama, Carbohydrate Polymers. 112, 195, (2014)

28. R. Muzzarelli, Carbohydrate Polymers. 84, 54, (2011)

29. M. Moharram, S. Khalil, H. Sherif, W. Khalil, Spectrochimica Acta Part A Molecular and Biomolecular Spectroscopy, 126, 1, (2014)
30. A. Travan, C. Pelillo, I. Donati, et al, Biomacromolecules, 10, 1429 , (2009).

31 A. Manikandan, M. Sathiyabama, J. Nanomed. Nanotechnol, 6, 1, (2015)

32. Powder Diffraction File, Inorganic Phases, International Centre for Diffraction data, Pennsylvania, USA. JCPDS 1997.

33. D. Chunfa; Z. Xianglin; C. Hao; C. Chuanliang, Rare Metal Materials and Engineering. 45, 0261, (2016)

34. D. Wei, W. Sun, Y. Qian, Carbohydrate Research. 344, 2378, (2009)

35. J. Creighton, D. Eadon, J. Chem. Soc. Faraday Trans. 87, 3881, (1981)

36. S. Nergiz, S. Singamaneni, Appl. Mater. Interfaces. 3, 945 (2011). 